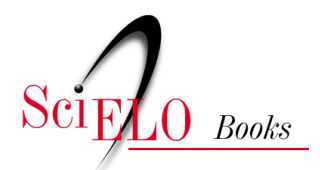

\title{
Uma crítica ao processo de autossegregação através da análise de três condomínios Minha Casa Minha Vida
}

\author{
Fábio Gustavo Pontes Martins \\ Marcelo Werner da Silva
}

\section{SciELO Books / SciELO Livros / SciELO Libros}

MARTINS, F. G. P., and SILVA, M. W. Uma crítica ao processo de autossegregação através da análise de três condomínios Minha Casa Minha Vida. In.: MAIA, D. S., and MARAFON, G. J., eds. O programa Minha Casa Minha Vida: habitação e produção do espaço urbano em diferentes escalas e perspectivas [online]. Rio de Janeiro: EDUERJ, 2020, pp. 269-288. ISBN: 978-6500-03029-7. https://doi.org/10.7476/9786500030297.0011.

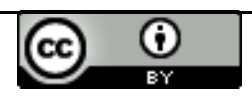

All the contents of this work, except where otherwise noted, is licensed under a Creative Commons Attribution 4.0 International license.

Todo o conteúdo deste trabalho, exceto quando houver ressalva, é publicado sob a licença Creative Commons Atribição 4.0.

Todo el contenido de esta obra, excepto donde se indique lo contrario, está bajo licencia de la licencia Creative Commons Reconocimento 4.0. 


\section{Uma crítica ao processo de autossegregação através da análise de três condomínios Minha Casa Minha Vida}

Fábio Gustavo Pontes Martins ${ }^{l}$

Marcelo Werner da Silva ${ }^{2}$

Introdução

O presente artigo visa aprofundar o debate a respeito do processo de segregação urbana com uma visão crítica do conceito de autossegregaçáo. Este debate se dará por meio da análise de três condomínios situados na cidade de Campos dos Goytacazes, produzidos no âmbito do maior programa habitacional do país, o Minha Casa Minha Vida (PMCMV), na modalidade empresarial.

É preciso frisar que a crítica que iremos fazer se circunscreve à realidade brasileira, não sendo nossa intenção desconstruir o arcabouço conceitual vigente sobre a questão da autossegregação ou reelaborá-lo sob novas bases. Também não o consideramos ultrapassado, apenas que não se aplica a todos os contextos que envolvem o morar em condomínios, principalmente quando estes são produzidos para os segmentos de menor renda em nosso país, como verificado no PMCMV.

Para cumprir este objetivo, vamos elaborar uma breve exposição do PMCMV, situando a natureza do maior programa habitacional brasileiro, que em nossa opinião é muito mais do que uma simples política habitacional do governo federal.

1 Professor de Geografia das redes públicas estadual e municipal, licenciado em Geografia e pós-graduado em Ensino de Geografia pelo Instituto Federal Fluminense e mestre em Geografia pela Universidade Federal Fluminense. E-mail: fgustavopontes@ gmail.com

2 Pós-doutorado pela Universidad de Barcelona, professor do Departamento de Geografia de Campos e do Programa de Pós-Graduação em Geografia (PPG) da Universidade Federal Fluminense, Campos dos Goytacazes - RJ. E-mail: marcelows@id.uff.br 
O passo seguinte será discutir o conceito de autossegregação, normalmente associado à autossegregação residencial dos estratos de renda média alta e alta em nosso país (Corrêa, 2004 e Souza, 1996), elaborando algumas questôes sobre alguns pontos que envolvem a produção imobiliária no contexto do PMCMV.

Por fim, realizaremos o contraponto que almejamos produzir à literatura que versa sobre o processo de autossegregação. Nesta etapa do trabalho, vamos, sempre que necessário, revisitar os conceitos discutidos à luz de uma realidade concreta, os residenciais Vida Boa Condomínio Clube Campos, Vida Bela Condomínio Clube Campos e Viva Vida Condomínio Clube Campos, todos na cidade de Campos dos Goytacazes - RJ.

\section{O Programa Minha Casa Minha Vida}

O Minha Casa Minha Vida é um programa habitacional federal de produção de moradias criado em março de 2009, por meio da Medida Provisória (MP-459), no governo do presidente Luiz Inácio Lula da Silva, do Partido dos Trabalhadores (PT). Ele foi o resultado de uma demanda do setor da construção civil (Rolnik, 2015), que almejava produzir 200 mil residências em nosso país.

Entre os seus objetivos, também estava minimizar os efeitos da crise do subprime. ${ }^{33}$ Em síntese, o PMCMV, em seu âmago, buscava muito mais gerar estímulos econômicos (Amore, 2015, p. 15), do que ser uma solução a um problema estrutural brasileiro que é a falta de moradias para famílias de baixa renda.

Mesmo considerando estas colocações iniciais, deve-se destacar que, por iniciativa do presidente Lula, o número de residências a serem construídas por meio do programa passou para 1 milhão, com enfoque também nas camadas de baixa renda, que recebem até 3 salários mínimos, que correspondem a $90 \%$ do déficit habitacional brasileiro e que, com o programa, poderiam adquirir uma residência quase totalmente subsidiada (Romagnoli, s/d) com recursos do Orçamento Geral da União (O.G.U.).

3 O subprime é uma crise do setor financeiro, de julho de 2007, em função da queda de Dow Jones e tem na sua origem a concessão de empréstimos hipotecários de alto risco. 
O Minha Casa Minha Vida encontra-se atualmente na sua Fase 3. A Fase 1 foi de março de 2009 à junho de 2011; a Fase 2 foi de junho de 2011 até dezembro de 2014 e a fase 3 teve início em 2016 com previsão de duração até dezembro de 2018, segundo o Governo Federal. ${ }^{44}$

O programa apresenta três faixas de rendas distintas. As Faixas 1 e 1,5 são compostas por famílias com rendimentos de até três salários mínimos, com a diferença de que na Faixa 1,5 os subsídios são menores do que na Faixa 1.

Já para os indivíduos e famílias com rendimentos superiores a 3 salários mínimos, inseridos nas Faixas 2 e 3, o PMCMV oferece condições mais vantajosas, tais como juros mais reduzidos que os praticados pelos bancos privados no país, por exemplo.

A Faixa 2 do PMCMV é composta por famílias cujo rendimentos variam entre 3 a 6 salários-mínimos, para as quais há a concessão de algumas vantagens para o acesso à moradia. Nessa faixa de renda, na terceira Fase do programa, o governo produziu algumas alteraçóes quando comparado às Fases 1 e 2 . Antes, o pretendente ao imóvel pelo programa obtinha um financiamento com juros girando em torno de $5 \%$ a $7,5 \%$ ao ano, dependendo da renda bruta familiar. $\mathrm{Na}$ fase 3 , os juros praticados pelo programa serão de $6 \%$ ou $7 \%$, dependendo sempre do rendimento familiar. Os adquirentes dos imóveis nesta faixa, além do benefício do crédito mais barato que os praticados pelo mercado, contam também com a garantia do pagamento da prestação por parte do Fundo Garantidor da Habitação (FGHab), de natureza privada (Rolnik, 2015), bem como de estímulos para a aquisição da moradia, como custos de seguro do imóvel reduzidos (Romagnoli, s/d). Neste caso, a produção imobiliária e o processo de aquisição é realizado pela empresa construtora, o que denota a diversidade de modalidades existentes dentro do mesmo programa habitacional.

O programa Minha Casa Minha Vida, portanto, apresenta diversas modalidades. A principal delas é a "Empresarial”, que detém a maior parte dos recursos do programa. As outras modalidades são a "Entidades", que engloba entidades da sociedade civil sem fins lucrativos, cooperativas ou associaçóes.

O público-alvo do programa consiste em famílias que tenham suas casas localizadas em áreas de risco, insalubres ou que tenham sido desabrigadas

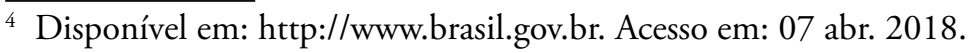


com a devida comprovação dos governos locais ou regionais. O MCMV-Entidades visa atender mulheres que sejam responsáveis pelos seus lares, desde que devidamente comprovado por autodeclaração; e de pessoas com deficiência física, devidamente atestada por um médico.

O Fundo de Arrendamento Residencial (FAR), é composto por recursos transferidos do Orçamento Geral da Uniáo (OGU) para viabilizar a construção de unidades habitacionais para famílias até $\mathrm{R} \$ 1.800,00$ e, diferentemente do Entidades, que visa uma produção imobiliária autogestionária, o FAR fundamenta-se na construçáo habitacional por meio de empresas do setor da construção civil e destina-se a famílias com renda mensal de até $\mathrm{R} \$ 1.800,00$ com as mesmas condiçóes verificadas no MCMV-Entidades.

O Programa Nacional de Habitação Rural (PNHR) visa atender famílias que tenham residências localizadas em áreas de risco, insalubre ou tenham sido desabrigadas, com a devida comprovação por agente público. Mulheres são uma prioridade do programa, desde que sejam responsáveis por seus lares, bem como de que façam parte da composição familiar indivíduos com deficiência. Entretanto, o Minha Casa Minha Vida Sub-50 criada para atender os menores municípios do país (Rolnik, 2015, p. 303).

\section{A autossegregação residencial}

A segregação urbana é o processo de marginalização ou de periferização de grupos ou indivíduos na sociedade, constituindo, segundo Alvarez (2013, p. 111), um dos fundamentos da produção do urbano capitalista.

Sua explicaçáo reside em fatores de ordem social, econômica, política, cultural, histórica e racial. Os exemplos mais evidentes deste processo no Brasil materializam-se em nossas favelas e nas periferias distantes dos principais núcleos urbanos, o que a literatura especializada classifica como segregaçáo imposta (Vasconcelos, 2013 e Corrêa, 2013). Esta segregação difere-se de maneira tênue da induzida, que é aquela em que existem algumas possibilidades de escolhas condicionadas ao preço das terras e dos imóveis (Corrêa, 2013, p. 43). A segregação induzida, ao contrário, não permite escolha alguma a não ser residir onde é possível.

É importante salientar que a segregação é um processo dialético (Villaça, 2001), na qual aqueles que se autossegregam - "os de cima” - em condomínios exclusivos, por exemplo, geram, por conseguinte, a segregação de 
outros - "os de baixo" - evidenciando a complexidade do processo que apresenta duas faces (Spósito, 2013, p. 69).

Os estudos mais recentes sobre a segregação se debruçam sobre o tema em trabalhos que têm como escopo os condomínios fechados (Rolnik, 1995; Villaça, 2011 e Souza, 2008). Várias pesquisas foram produzidas no campos da Antropologia (Caldeira, 2000), da Geografia (Corrêa, 2004) e da Sociologia (Villaça, 2001), entre outros, possibilitando aos pesquisadores do país um aprofundamento do processo, tendo por base a realidade nacional. Os exemplos mais eloquentes são os condomínios da Barra da Tijuca, na cidade no Rio de Janeiro, e Alphaville, em São Paulo (Souza, 1996).

Os trabalhos produzidos tornam evidente uma pluralidade de formas de segregação e seus autores cunharam diversas expressōes (Spóito, 2013, p. 69) para tratar deste processo, tais como espaços fechados e murados (Spósito e Góes, 2013), autossegregação (Corrêa, 2004), enclaves fortificados (Caldeira, 2000) ou autoenclausuramento (Souza, 2005). No entanto, da mesma forma que Spósito (2013), daremos preferência ao termo autossegregação.

Apesar desta profusão de trabalhos, isto não significa dizer que já tenhamos desnudado todos os aspectos que estáo envolvidos na questão, como aponta Villaça (2011), pois as abordagens recentes a respeito da segregaçáo em condomínios apresentam limitaçôes que necessitam de mais aprofundamento, posto que tocam, fundamentalmente, em temas como a insegurança (Spósito e Góes, 2013), a qualidade de vida e a dinâmica do mercado imobiliário (Pádua, 2015).

Este fato exemplifica a grande complexidade da autossegregação urbana, que outrora era apanágio das camadas de status social elevado de nossa sociedade, para as quais morar em condomínios cada vez mais afastados dos núcleos principais de nossas metrópoles e cidades médias não era um grande problema, uma vez que eram dotadas de grande mobilidade espacial e, sendo assim, a distância a se percorrer cotidianamente de suas casas para os locais de trabalho e lazer não era um complicador.

O que nos interessa é atestar que este novo padrão de produçáo de condomínios, como os do PMCMV, difere daquele destinados às elites, porque para elas, ao longo do século $\mathrm{XX}$, a busca pelo isolamento teve, como um de seus fundamentos, a separaçáo dos indivíduos de menor poder e prestígio social. 
Vemos que agora a autossegregação apresenta um novo conteúdo, avançando sobre os segmentos de renda média e baixa, somos levados a concordar com Spósito (2013), pois estamos assistindo a novas formas de segregação socioespacial com modificação no rumo que imperou na maior parte do século XX em relação ao conceito de segregação.

Esse novo conteúdo se relaciona à elevação do poder de compra, do consumo e ampliação do crédito aos indivíduos de renda média e baixa, propiciando que possam se inserir, mais satisfatoriamente, neste mercado de consumo. Tal fato foi potencializado pela política de juros mais baixos e crédito subsidiado pelo governo, como é o caso do PMCMV, possibilitando a elevação no padrão da habitação dos indivíduos de menor poder aquisitivo, cuja autossegregação popular sempre tendeu à "periferização" de suas casas (Spósito, 2013).

Mas aí reside um novo fato. Ele se exprime, ao nosso ver, no fato que a autossegregação em condomínio não é mais uma exclusividade das elites. Entretanto, questionamo-nos até que ponto o conceito pode ser aplicado à realidade dos imóveis destinados às famílias de menor poder aquisitivo.

Os residentes do Vida Boa Condomínio Clube Campos, Vida Bela Condomínio Clube Campos e Viva Vida Condomínio Clube Campos, construídos no âmbito do PMCMV, são exemplos de autossegregação semelhantes aos condomínios da Barra da Tijuca, no Rio de Janeiro, ou Alphaville, em São Paulo?

Teriam eles as mesmas possibilidades de acesso a bens e serviços, empregos, mobilidade no espaço urbano, ou mesmo status, condiçóes de aquisição dos imóveis e o prestígio no morar que desfrutam os condomínios de luxo? Se a resposta é negativa, também é inegável que em ambos os casos verifica-se a autossegregação, aproximando os dois casos.

Sendo assim, nos perguntamos: os condomínios produzidos no âmbito do PMCMV são uma evidência irrefutável da autossegregação? Os condomínios produzidos pelo PMCMV se enquadram nesta definiçáo? São eles mais um exemplo deste processo ou seriam uma expressão da segregação induzida? Os seus residentes dispóem dos mesmos recursos financeiros e de mobilidade que as classes médias e as elites nacionais que perfazem o público-alvo deste modelo de moradia? Ou estaríamos diante de um processo de exclusão socioespacial e não o contrário como a literatura nos leva a crer? Tais questóes se somam as indagaçóes suscitadas por Villaça (2011): 
Em que os condomínios fechados se distinguem das tradicionais formas de segregação, por classe e por bairro, que existem há mais de um século em nossas cidades? Em que se distinguem do Jardim América, Pacaembu ou Alto de Pinheiros? Só no tocante à proteção contra violência? Aos controles de portaria? À produção imobiliária? No tocante à novidade imobiliária, eles em nada se distinguem desses bairros há 50 ou 80 anos atrás. [...] Em que e por que esses aspectos são algo novo? Claro que são novos. A questão é, insistimos, se são significativamente novos. Em que e por quê são relevante e irrelevantes? Como integrar sua análise a processos socioespaciais mais amplos? Como interpretar os condomínios fechados superando a denúncia e os interesses dos moradores? (p. 39).

Para determinar todas essas questóes é indispensável o aprofundamento in locu com os residentes dos condomínios, na medida que a discussão teórica aqui encontra seu limite, que será sanada pelo recurso da análise empírica.

\section{O Vida Boa, Vida Bela e o Viva Vida Condomínio Clube Campos: uma possibilidade de crítica ao conceito de autossegregaçáo residencial}

A questão que formulou o presente artigo pauta-se numa visão formulada a partir de três condomínios produzidos pela construtora PDG (vide figuras 1, 2 e 3), no âmbito do Programa Minha Casa Minha Vida, no bairro do Jockey Club, cidade de Campos dos Goytacazes - RJ, que nos permitem elaborar uma crítica ao processo de autossegregação.

Tal análise fundamenta-se, num primeiro momento, no tipo de imóvel construído, sua localização periférica na cidade, perfil dos moradores detectado através de entrevistas ${ }^{55}$ e observaçóes in loco e o próprio fato de estarem inseridos em um programa habitacional do Governo Federal, no âmbito do Minha Casa Minha Vida.

5 Foram realizadas 15 entrevistas entre moradores dos condomínios e os residentes da rua João Manoel de Faria. O número se apoia na metodologia elaborada por Bauer e Gaskel (2008), que enfatizam que, para um pesquisador individual, a quantidade deve girar entre 15 a 20 entrevistas em função do número de versóes da realidade e do tamanho do corpus a ser analisado. 
Figuras 1, 2 e 3 - Vida Boa Condomínio Clube Campos, Vida Bela Condomínio Clube Campos e Viva Vida Condomínio Clube Campos
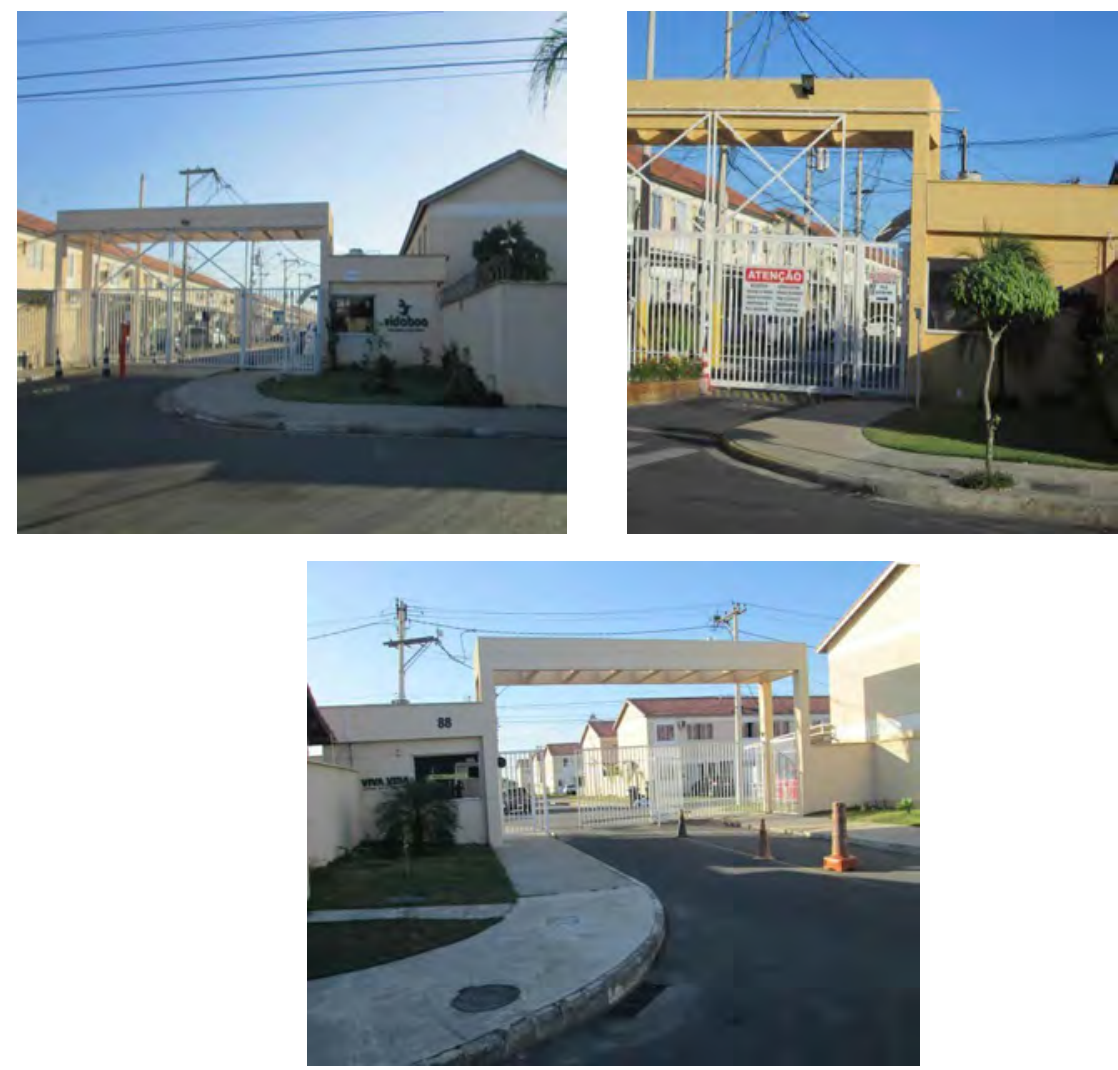

Fonte: Fábio Gustavo Pontes Martins.

Porém, antes de tudo, retomemos a literatura a respeito do processo de segregação para que nossa exposição fique mais evidente. A segregação manifesta-se no espaço urbano por meio da formação de espaços distintos na cidade (Rolnik, 1998), sendo uns mais associados às elites e outros à classe trabalhadora, por exemplo.

No primeiro caso, temos como maior forma de manifestação no presente momento os condomínios exclusivos (Villaça, 2011), ao passo que, para o segundo, observamos as periferias autoconstruídas, favelas, cortiços (Kowarick, 1979) que abrigam uma porção numerosa da população pobre deste país, as quais experimentam, mais do que ninguém, os efeitos da exclusão social. 
$\mathrm{Na}$ cidade capitalista a segregação está relacionada às diferenças de classes e a localização destas no espaço urbano. É neste espaço que se verifica como as classes utilizam e se apropriam de espaços localmente diferenciados. Quem pode pagar mais escolhe onde e como morar. Aqui surge também uma dura realidade das cidades brasileiras que é a questão da habitação (Filho et al, 2009, pp. 2-3).

O conceito de segregação, destaca Spósito (2013, p. 64) é multidimensional. A autora pauta cinco pontos na caracterização da segregação: a) Nem todas as formas de diferenciação e desigualdades são necessariamente formas de segregação; b) há múltiplas formas de adjetivá-la; c) a segregação é sempre de natureza espacial; d) a segregação é um processo; f) a segregação estabelece uma mescla de condicionantes e expressóes objetivas e subjetivas.

Spósito (2013, p. 66) advoga que prefere o termo segregação socioespacial e informa que tal escolha relaciona-se ao fato do conceito congregar as duas dimensóes, as quais estáo em consonância com o terceiro item. A segregação é sempre de natureza espacial "e, por esta razão, ela se distingue da discriminação, da estigmatização, da marginalização, da exclusão, da espoliação ou da pobreza, que podem ter expressão espacial, mas se constituem, estruturalmente, em outros planos: o social, o econômico, o político, o cultural, etc." (Spósito, 2013, p. 66).

A questão se torna mais complexa quando percebemos que fatores como os subsídios para a aquisição de imóveis, os juros mais baratos no PMCMV do que os oferecidos pelos bancos privados, a ampliação do crédito ao longo do governo do Partido dos Trabalhadores (PT) etc., possibilitaram que segmentos da sociedade, outrora negligenciados pelo mercado formal de moradias, adquirissem residências na modalidade condominial, que a princípio configurava-se como um típico processo de autossegregação.

A autossegregação é resultado de uma decisão voluntária de reunir grupos socialmente homogêneos, cujo melhor exemplo é o loteamentos e condomínios fechados, com suas entradas restritas, muros e sistemas de segurança. É uma forma radical de agrupamento residencial defensivo que procura juntar os semelhantes e excluir os diferentes e impedir o acesso dos indesejáveis (Vasconcelos, 2013, p. 27). 
A despeito das políticas públicas habitacionais, historicamente, elas reproduzem e referendam o processo de segregação socioespacial, pois as moradias populares, regra geral, são produzidas muito distantes da área central da cidade e, consequentemente, dos serviços urbanos que a sociedade necessita (Filho et al., 2009, pp. 2-3).

Os imóveis do programa Minha Casa Minha Vida em Campos dos Goytacazes evidenciam o fato de que a produção imobiliária ensejada por políticas públicas tem como tônica uma localização afastada das áreas centrais das cidades, em bairros de periferia. São imóveis com dimensóes reduzidas e que em muitos casos impedem a realização de alteraçóes.

No condomínio Viva Vida, para enfocar em um único exemplo, é vedada qualquer alteração na planta da casa, que detém dimensóes reduzidas, com cerca de $60 \mathrm{~m}^{2}$ de área construída, sendo apenas dois quartos e cerca de $80 \mathrm{~m}^{2}$ de área utilizável. Assim sendo, uma família que tenha o segundo ou terceiro filho ficará em imóvel incompatível com a sua configuração.

A segregação assim redimensionada aparece com um duplo papel, o de ser um meio de manutençáo dos privilégios por parte da classe dominante e o de um meio de controle social por esta mesma classe sobre os outros grupos sociais, especialmente a classe operária e o exército industrial de reserva (Corrêa, 2004, p. 64).

Ao nosso ver os condomínios Vida Boa, Vida Bela e Viva Vida não são uma expressão cabal de um processo de autossegregaçáo como explicado pela literatura especializada sobre o tema e como pode sugerir um primeiro vislumbre desses condomínios. Se eles não são uma evidência do processo, que tipo de segregação podemos constatar em sua observação?

Vejamos, mais uma vez, o que diz a literatura sobre tema. A autossegregação "caracteriza-se como uma política de classe e liga-se diretamente aos estratos superiores classe média [...] e implica, ao menos por parte de membros do grupo de alto status, controle, em maior ou menor grau, do aparelho de Estado, das principais atividades econômicas, melhores terras urbanizáveis e da empresas imobiliárias (Corrêa, 2013, p. 43, grifo nosso).

Spósito e Góes (2013, p. 281) indicam que autossegregação está atrelada aos estratos sociais com melhores condições financeiras, que escolhem se isolar do conjunto da cidade que, na visão deles, "é o espaço dos outros e, portanto, náo mais de todos". 
De forma geral a tônica na fala de Corrêa (2013), Souza (2013) e Spósito e Góes (2013) indica que a autossegregação é um processo no qual seus principais atores são os indivíduos que estão inseridos nas camadas de alto status, o que é diametralmente oposto ao verificado no Vida Boa, Vida Bela e Viva Vida Condomínio Clube Campos.

Sendo assim, quando cotejamos a literatura com a realidade concreta, o que se percebe é que de um lado há os condomínios exclusivos onde a elite reside, já nos três condomínios estudados, temos indivíduos muito mais identificados com a Nova Classe Trabalhadora, uma vez que seus rendimentos, empregos e escolaridade, por exemplo, estáo aquém daqueles percebidos tradicionalmente pela classe média

Questionamos também se todos os condomínios produzidos no âmbito do programa Minha Casa Minha Vida se enquadram no referido processo de autossegregação, mas quanto a isso devemos enfatizar que toda forma de generalização é sempre temerária, seja em função da grande diversidade de imóveis produzidos e por não dispormos de dados relativos à todos os empreendimentos Minha Casa Minha Vida.

No caso específico que estudamos, somos levados a afirmar que náo é um típico processo de autossegregação residencial, portanto não se configura como um exemplo desse fenômeno. O leitor deve estar se perguntando que, se eles não são uma manifestação da autossegregação e se os condomínios PMCMV compóem um quadro de enorme diversidade, que processos evidenciam o Vida Boa, Vida Bela e o Viva Condomínio Clube Campos?

A segregação é um processo dialético (Villaça, 2001) e, como vimos em (Souza, 2008), o autoenclausuramento está associado aos segmentos de maior renda. No entanto, quando nos referimos aos segmentos de menor poder aquisitivo, a segregação resulta de uma política de classe, como aponta Corrêa (2013, p. 43), mas elaborada pelos indivíduos de maior poder na sociedade.

Revisitando mais uma vez a teoria, temos duas situaçôes: a segregação imposta e a induzida (Corrêa, 2013, p. 43). O primeiro caso tem sua expressão quando indivíduos e famílias vão morar onde lhes é imposto, uma vez que suas condiçóes financeiras não permitem escolhas e, na maioria das vezes, a alternativa é a favela ou as periferias distantes. Já no segundo, temos a segregação induzida. Neste caso, as famílias e os indivíduos têm opçôes de escolha até um certo limite circunscrito ao preço do imóvel e da terra. 
Nas entrevistas realizadas, constatamos a situação descrita anteriormente na forma de uma segregaçáo induzida, uma vez que nas respostas que obtivemos dos entrevistados sobre o porquê de terem escolhido aquela forma de moradia, a maioria concentrou-se no preço do imóvel e nas condiçóes de pagamento. Vejamos:

Entrevistada: Facilidade de pagamento da entrada; entrada facilitada dividida em 16 vezes. É [...] que a gente não tinha dinheiro para a entrada da compra do imóvel próprio. (Márcia, 39 anos, professora universitária e moradora do Viva Vida Condomínio Clube Campos, grifo nosso).

As três respostas a seguir sobre a mesma questão dão o tom do quão importante é a questão do preço do imóvel e como ele é o elemento central que levou os moradores a adquirirem uma residência naquele condomínio/bairro:

Entrevistado: Rapaz foi situação mais fácil de dar entrada foi na, na época, entendeu? Por causa da questão do dinheiro. (Paulo, 27 anos, Eletricista de Rede e Morador do Viva Vida Condomínio Clube Campos, grifo nosso).

Entrevistado: Foi o preço e o imóvel. Gostei muito da casa. (João, 54 anos, aposentado e morador do Vida Bela Condomínio Clube Campos).

Entrevistado: Preço e forma de pagamento. (Adilson, 41 anos, e morador do Vida Bela Condomínio Clube Campos, grifo nosso).

Só um dos entrevistados tocou na temática de segurança quando questionado do porquê da escolha daquela forma de moradia. Em nosso entendimento, isto deve-se ao fato de que a violência na cidade de Campos dos Goytacazes concentra-se em bairros do subdistrito de Guarus, que concentra a populaçáo de baixa renda, sendo que a maior parte dos entrevistados tem uma origem em bairros do subdistrito do centro, que náo registram os casos mais graves de crimes na cidade, como os assassinatos cotidianos.

Entrevistado: Tamanho do imóvel e o sossego. Atende melhor [...] e sistema de condomínio, segurança. (Arivaldo, 63 anos, Técnico Eletricista, Pintor, Pedreiro e morador do Vida Bela Condomínio Clube Campos, grifo nosso). 
No que tange ao status social que se tem ao residir em condomínio, as respostas foram esclarecedoras e os entrevistados foram unânimes em destacar que não percebem um status social elevado por terem como local de residência um condomínio.

Entrevistada: Sim e depende do condomínio também, né? Entrevistador: Por quê? Entrevistada: Eu acho que tem muito mais a ver com uma questáo estética do condomínio. Então, por exemplo, este condomínio (Viva Vida) esteticamente é desfavorecido. Ele está na margem da cidade, ele tem, ele não confere status. Eu acredito nisso, mas ele apresenta outros benefícios; Entrevistador: Como? Entrevistada: Segurança, o principal deles. (Márcia, 39 anos, professora universitária e moradora do Viva Vida Condomínio Clube Campos, grifo nosso).

No entanto, quando questionados se sentem-se privilegiados por morarem em condomínios, a maioria respondeu que sim. Nesta pergunta, o tema violência de certa forma se impôs e vários entrevistados destacaram este fato, apesar da violência não ter sido a razão que os levou a adquirir os imóveis como vimos acima.

Entrevistada: Sim. Por exemplo, eu estou procurando casa para comprar e eu quero continuar morando em condomínio. Por que? Porque a gente tem um problema crônico nessa cidade que se chama Terceiro Comando Puro (TCP), A.D.A. (Amigos dos Amigos). A cidade é dividida por muros invisíveis que aparecem pichados nas casas, ninguém faz nada, a polícia não funciona. (Márcia, 39 anos, professora universitária e moradora do Viva Vida Condomínio Clube Campos) ${ }^{66}$

Como vimos, apesar do tema violência ter sido considerado, as razóes que levaram os segmentos de maior renda a se autossegregarem não explicam a aquisiçáo do imóvel pelos residentes entrevistados. Temos, entáo, mais um elemento para embasar a nossa argumentação, de acordo com a qual os condomínios Vida Boa, Vida Bela e Viva Vida não se configuram como um processo

${ }^{6}$ Segundo Latuf $(2015$, p. 123), "Por facçôes criminosas deve-se entender, ao menos durante a leitura do presente artigo, que se trata de um grupo de pessoas que, por partilharem de uma mesma realidade (estarem encarcerados), organizou-se". 
de autoenclausuramento típico. Também não se trata de uma forma de exclusão socioespacial que a princípio tínhamos aventado, apesar da segregação e da exclusão serem processos que mantêm uma correlação entre si, como aponta Sposati (1998), o que não significa dizer que estamos diante dela.

A exclusão alcança valores culturais, discriminaçôes. Isto não significa que o pobre não possa ser discriminado por ser pobre, mas que a exclusão inclui até mesmo o abandono, a perda de vínculos, o esgarçamento das relaçóes de convívio, que necessariamente não passam pela pobreza (Sposati, 1998, pp. 3-4).

Nossa primeira formulação fundamentava-se em dois princípios. $\mathrm{O}$ primeiro referia-se à localização dos imóveis, situados no fim de uma antiga rua sem saída que tinha como limite um vazio urbano. $\mathrm{O}$ segundo associava-se à limitada disponibilidade de serviços e equipamentos urbanos nas proximidades dos condomínios, fato que obriga seus residentes a caminharem distâncias consideráveis para acessar o transporte público de modo que possam se dirigir ao centro da cidade e outros locais em que possam ter acesso a bancos, hospitais, universidades, cinemas, shopping, entre outros. Esta característica nos leva a concordar com Pontes (2018, p. 2) para quem

[...] a acessibilidade é condicionada pela interação entre o uso do solo e o transporte, e que se constitui num importante indicador de exclusão social ao lado da mobilidade, da habitação, da educação e da renda. A acessibilidade ou a falta dela, ao ser parte integrante e fundamental da dinâmica e do funcionamento das cidades, passa a ser um elemento que contribui para a condição de exclusão/inclusão socioespacial, na medida em que facilita o acesso da população aos serviços e equipamentos urbanos, além de viabilizar sua aproximação com as atividades econômicas (Pontes, 2018).

Todos os nossos entrevistados possuem automóveis e os utilizam como principal meio de locomoção na cidade. Eles podem usufruir dos serviços públicos que ela oferece sem maiores problemas, o que significa que para eles o local de residência não se configura como um fator de limitação para uso do espaço citadino, algo táo associado aos que detém parcos recursos e ficam presos ao lugar (Bourdieu, 2001). Porém, isto não significa que todos os residentes dos condomínios possuam automóveis, pois parcelas considerá- 
veis dos moradores têm como meio transporte bicicleta ou andam a pé até o ponto de ônibus.

Quando buscamos outros aspectos relacionados à exclusão, como a baixa escolaridade e o desemprego (Oliveira, 1997), por exemplo, vemos que nossos entrevistados apresentam uma situação diametralmente oposta, na qual há uma grande predominância de indivíduos com formação superior, bem como empregos no serviço público. Oliveira (1997, p. 3) destaca ainda que, no Brasil, os excluídos são "os moradores e meninos de rua, os desempregados das favelas e periferias, muitos convertidos em flanelinhas e mesmo delinquentes, os catadores de lixo, etc. Mais do que simplesmente pobres, eles estão mais próximos do que normalmente designamos miseráveis" (Grifo nosso).

Dos entrevistados, apenas três receberam o subsídio governamental. Mesmo assim, não estamos afirmando que eles tenham uma renda muito elevada, sendo, portanto, de uma classe social superior. Os próprios entrevistados atestaram que não e a maioria se via como parte integrante da classe trabalhadora. Porém, este fato é mais um elemento que se soma aos já destacados por nós, que tem como finalidade compor um panorama geral do que estamos investigando.

Após o exame das entrevistas, das análises de campo e da forma como os imóveis foram adquiridos pelos entrevistados fomos levados à seguinte conclusão: de que ali temos algo mais próximo de uma segregação induzida do que um processo de exclusão socioespacial que a princípio tínhamos sugerido ou propriamente uma autossegregação.

A afirmaçáo anterior tem como embasamento os pressupostos apresentados a seguir. Primeiro, não se observa no Vida Boa, Vida Bela e Viva Vida Condomínio Clube Campos um típico processo de autossegregação, uma vez que os residenciais não se caracterizam por elementos de exclusividade e não foram destinados aos privilegiados de nossa sociedade. Este aspecto é relevante, pois como atesta a literatura especializada em autossegregação, em condomínios é um processo ligado a setores da classe média e da elite, cujos grandes exemplos são os empreendimentos localizados na Barra da Tijuca, na cidade do Rio de Janeiro, e o complexo Alphaville, na regiáo metropolitana de São Paulo (Souza, 1996).

Segundo: os residentes dos condomínios não podem ser vistos como excluídos de maneira alguma, ainda que pese o fato de morarem em um bairro periférico com serviços públicos precários, como eles próprios atesta- 
ram. Temos que levar em consideração que eles fazem uso dos equipamentos públicos existentes em outras partes da cidade com auxílio de um meio de locomoção individual, pois dada as condiçôes de localização dos condomínios é um recurso de primeira ordem.

O automóvel conformou as cidades e definiu, ou pelo menos foi o mais forte elemento a influenciar, o modo de vida urbano na era da industrializaçáo. Aquilo que era inicialmente uma opção - para os ricos, evidentemente - o automóvel passou a ser uma necessidade de todos (Maricato, 2014, p. 171).

Recorrendo às entrevistas que realizamos nos condomínios citados, constatamos uma grande homogeneidade entre eles; porém, nas observaçóes de campo, verificamos inúmeros casos que expuseram uma grande diversidade no interior dos condomínios. A pesquisa de campo apontou uma série de indícios que sáo indicativos da variedade existente no interior dos condomínios, uma vez que constatamos a ocorrência de residentes saindo de suas casas para o trabalho a pé, de bicicleta e de carro. Percebemos que alguns residentes vão ao trabalho de uniforme, e ao mesmo tempo conversamos com uma professora da Universidade Estadual do Norte Fluminense (UENF), doutora em Antropologia, moradora do Viva Vida Condomínio Clube Campos e que reside no local com seu marido, também professor da referida instituição.

A necessidade do automóvel para os residentes dos condomínios é muito evidente em função da sua localização e da própria limitação do bairro do Jockey Club na oferta de bens e serviços. Para termos uma compreensão melhor, o ponto de ônibus mais próximo que se destina ao centro da cidade de Campos dos Goytacazes encontra-se a cerca de um quilômetro de distância, na BR-356, no trecho denominado de Avenida Presidente Kennedy.

Com tais condiçóes, o carro é um recurso de primeira ordem para os residentes dos condomínios. Esta constatação foi possível dada a grande quantidade de veículos estacionados nas garagens dos moradores: "sem o automóvel não há como abastecer uma casa na cidade marcada pela urbanização dispersa: ocupação de vastas áreas com baixa densidade de ocupação onde predomina, no uso do solo, frequentemente de forma absoluta e exclusiva, a moradia e a infraestrutura rodoviária" (Maricato, 2014, pg.172). 
Os entrevistados têm um perfil marcado por pessoas com formação superior, majoritariamente composto por funcionários públicos de carreira, sendo, portanto, com trabalhos estáveis.

O terceiro ponto é, ao nosso ver, o mais central de todos os elementos que destacamos para corroborar a afirmação segundo a qual os condomínios podem exprimir um processo de segregação induzida. Por quê? Porque o processo que estamos diante foi induzido pelo preço dos imóveis e pelas condiçóes de pagamento obtidas pelos nossos entrevistados e como aponta Corrêa (2013, p. 43), a segregação induzida é verificada naqueles que ainda têm escolhas possíveis, mas tais escolhas apresentam-se dentro de determinados limites com o preço do solo e dos imóveis.

Vejamos: O que levou o senhor (a) a escolher esta forma de moradia?

Entrevistado: Foi o preço e o imóvel. Gostei muito da casa. (João, 54 anos, aposentado e morador do Vida Bela Condomínio Clube Campos, grifo nosso).

Não pretendemos ser diversionistas com as entrevistas e, com isso, tentar manobrar e enquadrar um conceito a partir das respostas obtidas. As informaçôes se casaram de tal forma que não poderíamos negligenciar o fato segundo o qual temos uma ação - a compra do imóvel - por parte dos moradores, que teve como grande elemento condicionador o preço da casa e as condiçóes de pagamento e financiamento verificados.

Sendo assim, somos levados mais do que nunca a assumir uma posição em que estamos diante de um cenário muito mais próximo de uma segregação induzida do que, por exemplo, uma autossegregação ou exclusão socioespacial. Estamos convictos de todos os riscos que tal postura traz, uma vez que seria um tanto insólita a afirmação feita por nós, porque condomínios sempre são associados com autossegregação ou condomínio para classes de alto status social e econômico. Porém, a sociedade não é estática e as mudanças são verificadas exigindo uma reformulação dos conceitos produzidos para explicar uma dada situação, que atualmente encontra-se em franca transformação do seu conteúdo.

Não pretendemos aqui dizer que a teoria a respeito da autossegregação está incorreta, porém, dadas as atuais condiçóes de produção imobiliária, que vêm avançando por meio dos segmentos de menor renda pertencentes à 
Nova Classe Trabalhadora, estamos sendo levados a questioná-la, pois ela não seria capaz de explicar como condomínios como o Vida Boa, Vida Bela e o Viva Vida Condomínio Clube Campos configuram-se muito mais como um processo de segregação induzida do que propriamente uma autossegregação, como a teoria nos leva a crer.

Para nós, essa teoria é totalmente capaz de explicar o processo quando se parte da premissa básica que o objeto a ser estudado é especificamente os destinados ao segmento de alto status, o que evidentemente não é o nosso caso. $\mathrm{O}$ nosso objeto de estudo, produzido no âmbito do programa Minha Casa Minha Vida, maior programa habitacional do país, destina-se a um outro público composto por indivíduos das mais variadas origens que vão desde uma acadêmica, passando por um técnico especializado e culminando em um empregado de uma importante rede de supermercados da cidade.

Nosso objeto de estudo é a expressão de uma produção imobiliária caracterizada pela impessoalidade nas residências, com construção padronizada, estandardizada, em escala, com valores de venda reduzidos no mercado residencial - se compararmos aos condomínios exclusivos -, mas foram eles em última instância, o elemento definidor da aquisição da casa - por exemplo, o valor da prestaçáo, a forma de pagamento, se caberia ou não orçamento familiar. Em função deste fato, dissemos que o Vida Boa, Vida Bela e o Viva Vida Condomínio Clube Campos caracterizam um processo de segregaçáo induzida, ainda que a literatura especializada diga o contrário.

\section{Consideraçóes Finais}

O presente artigo buscou aprofundar a problemática envolvida no processo de autossegregação residencial e questionar, em certo grau, a aplicação do conceito, uma vez que cada vez mais assistimos um avanço do capital imobiliário em nossas cidades, onde, a cada dia que passa, novos produtos imobiliário são lançados com o intento de se alcançar todos os públicos possíveis.

Este fato, devemos frisar, se impóe aos que se dedicam à problemática em tela uma nova visão a respeito do processo de autossegregação, que é, ao nosso ver, um conceito passível de ressalvas, uma vez que sua aplicação a cada dia que passa sujeita a questionamento todos aqueles que se dedicam à tarefa de desnudar o urbano, com todas as suas especificidades encontradas em cidades de um país como o Brasil. 
Contudo, queremos deixar claro que não temos a pretensão de negar a aplicabilidade do conceito de autossegregação, mas achamos que sua eficácia como recurso analítico no cenário atual, em que há uma avanço quase que implacável do capital imobiliário no segmento de menor renda em nosso país, deve ser questionada. Advogamos a tese segundo a qual o conceito, para ser aplicado, sem prejuízo analítico, deve ficar mais condicionado aos imóveis que têm como alvo os segmentos de maior renda.

\section{Referências}

ALVAREZ, Isabel Pinto. "A segregação como conteúdo da produção do espaço urbano". In: BAUER, Martins W. e GASKEL, George. Pesquisa qualitativa com texto, imagem e som: um manual prático. Petrópolis, RJ: Vozes, 2008.

BOURDIEU, Pierre. "Efeitos do lugar". In: (coord.). A miséria do mundo. 4 ed. Petrópolis: Vozes, 2001.

CALDEIRA, Teresa Pires do Rio. Cidades de muros: crime, segregação e cidadania em São Paulo. São Paulo: Ed. 34/Edusp, 2000.

CASTELLS, Manuel. A questão urbana. Rio de janeiro: Paz e Terra, 1983.

CORRÊA, Roberto Lobato. O espaço urbano. São Paulo: Editora Ática. São Paulo, 2004. . "Segregação Residencial: classes e espaço urbano". In: VASCONCELOS, Pedro de Almeida et al. (orgs.). A cidade contemporânea: segregação espacial. São Paulo: Contexto, 2013. pp. 38-59.

KOWARICK, Lúcio. A espoliação urbana. Rio de Janeiro: Paz e Terra, 1979.

LATUF, Julia Rosa. "Garantismo e faç̧óes criminosas: correlação da teoria Garantista com o surgimento e existência do Primeiro Comando da Capital". Revista Liberdades, n. 20, pp. 107-33, set.-dez. 2015.

MARICATO, Ermínia. O impasse da politica urbana no Brasil. Petrópolis, RJ: Vozes, 2014. 3. ed.

OLIVEIRA, L. "Os excluídos existem?: notas sobre a elaboração de um novo conceito". Revista Brasileira de Ciências Sociais, São Paulo, v. 12, n. 33, pp. 49-61, 1997.

PÁDUA, Rafael Faleiros de. "Produção estratégica do espaço e os 'novos produtos imobiliários”. In: CARLOS, Ana Fani Alessandri et al. (orgs.). A cidade como negócio. São Paulo: Contexto, 2015.

PONTES, Eduardo. Exclusão socioespacial, acessibilidade e mobilidade: notas para uma análise da Regiāo Metropolitana do Rio de Janeiro pela ótica do sistema de transportes, no contexto dos grandes eventos esportivos. Disponível em: http://www.chaourbano.com.br/visualizarArtigo. php?id=68. Acesso em: 11 jan. 2018.

ROLNIK, Raquel. O que é cidade. São Paulo: Brasiliense, 1998.

. Guerra dos lugares: a colonização da terra e da moradia na era das finanças. Sáo Paulo: Boitempo, 2015. 
ROMAGNOLI, Alexandre J. O programa "minha casa, minha vida”: continuidades, inovações e retrocessos. Disponível em https://periodicos.fclar.unesp.br. Acesso em 12 jan. 2018.

SOUZA, Marcelo Lopes de. Urbanização e desenvolvimento no Brasil atual. Editora Ática. São Paulo, 1996.

. O desafio metropolitano: um estudo sobre a problemática sócio-espacial nas metrópoles brasileiras. Rio de Janeiro: Bertrand Brasil, 2005.

. Fobópole: o medo generalizado e a militarização da questão urbana. Rio de Janeiro: Bertrand Brasil, 2008.

SPOSATI, A. "Exclusão social abaixo da linha do Equador". Seminário sobre exclusão social - PUC/SP, abr. 1998. Disponível em: http://www.dpi.inpe.br/geopro/exclusao/exclusao. pdf. Acesso em 21 fev. 2018.

SPÓSITO, Maria Encarnação Beltrão. “Segregação socioespacial e centralidade urbana”. In: VASCONCELOS, Pedro de Almeida et al. (orgs.). A cidade Contemporânea: segregação espacial. São Paulo: Contexto, 2013. pp. 61-93.

e GÓES, Eda Maria. Espaços fechados e cidades: insegurança urbana e fragmentação socioespacial. Sáo Paulo: Editora Unesp, 2013.

VASCONCELOS, Pedro de Almeida. "A aplicação do conceito de segregação residencial ao contexto brasileiro na longa duração". Cidades, Presidente Prudente. v. 1, n. 2, pp. 259-74, 2004.

. "Contribuição para o debate sobre processos e formas espaciais nas cidades". In: VASCONCELOS, Pedro de Almeida et al. (orgs.). A cidade Contemporânea: segregação espacial. Sáo Paulo: Contexto, 2013, pp. 17-37.

VASCONCELOS FILHO, João Manoel et. al. "A segregação sócio-espacial e a luta pelo direito a moradia: em foco a ocupação do setor Monte Sinai em Araguaína - TO”. In: Jornada Internacional de Políticas Públicas, IV, São Luís-MA: UFMA, 2009.

VILLAÇA, Flávio. Espaço intra-urbano no Brasil. São Paulo: Studio Nobel; Fapesp; Lincoln Institute, 2001.

. "São Paulo: segregação urbana e desigualdade". Estudos Avançados, n. 25, v. 71, pp. 37-58, 2011. 